\title{
Plasmid Profile and Antimicrobial Susceptibility Pattern of Staphylococcus sp. Isolated from High Touch Areas within the University of Port Harcourt Nigeria
}

\author{
O.E. Agbagwa* and O.C. Ibeachu \\ Department of Microbiology, Faculty of Science, \\ University of Port Harcourt Rivers State, Nigeria \\ *Corresponding author
}

\begin{abstract}
A B S T R A C T
\end{abstract}
The present study was conducted to determine and to compare the microbial population of ATM and computer keyboard within the University of Port Harcourt and also to determine the role of plasmid and resistance in Staphylococcus sp isolated from the high touch areas. A total of 70 swabbed samples was collected and cultured on different media and the

\section{Keywords}

Antibiotics, Disc diffusion, High touch area, Plasmid profile, S. aureus.

\section{Article Info}

Accepted: 26 September 2017 Available Online: 10 November 2017 organisms were identified using its colonial, morphological biochemical characteristics. The identified bacteria were subjected to antibiotic sensitivity test using the disc diffusion method. The plasmid of isolated $S$. aureus was cured by treatment with acridine orange. Results obtained from the study indicated that some of the ATM and the keyboards were positive for the presence of microorganisms which include Staphylococcus aureus, Streptococcus sp, Klebsiella sp, Escherichia coli, Pseudomonas sp and Micrococcus sp. The antibiogram study was carried out on the identified organisms and the result showed that majority of the bacteria were resistant to most of the standard antibiotics including cloxacillin, followed by augmentin, erythromycin, tetramycin, and streptomycin. Staphylococcus sp were subjected to plasmid profiling with the use of acridine orange to detect the role of plasmid in their resistance and its was observed that they were susceptible to chloramphenical (98\%), Gentamycin (94\%), cotrimoxazole (78\%), streptomycin (60\%), tetramycin (58\%), augmentin (52\%) and cloxacillin (40\%) because some antibiotic markers in Staphylococcus isolates are plasmid mediated . Hand washing after ATM and computer usage should be adopted to avoid contamination.

\section{Introduction}

Today, ATMs are widely used by many people, and they tend to harbor the microorganisms on their surfaces. The hand borne transmission through ATM is one of the most important routes for the spread of infectious agents in the community (Forbes $e t$ al., 2012). Contamination occurs everywhere including environment and all its objects. Computers keyboards and mouse, ATM keyboards, escalator handrails and other high touch areas are the most open surface parts of computer which show 100\% contamination. Computers continue to have an increased presence in almost every aspect of our occupational, recreational and residential environments. They are used in almost every facility, in various university environments, students have indicated $100 \%$ access to computers, $92.1 \%$ regularly use internet and $73.3 \%$ regularly use e-mail especially in 
developed countries (Palmer and Bray, 2001). The ability of these high touch areas may act as a reservoir for the transmission of potential hazardous or pathogenic microorganisms (Hartman et al., 2004). Inanimate surfaces can act as fomites, studies on this has been carried out previously in hospital and community environment (Huber and Pelon, 2005). About $80 \%$ of infections are spread through hand contact with hands or other objects.

Most high-touch areas are touched by the bare hands of people who are in various hygienic conditions. People most times believe that microbes are only present in research labs or in hospitals and clinics and often have a misleading feeling of security in other places. Lack of knowledge of the source of germs could be the main cause of health problems (Reynolds et al., 2000). Bacteria can be transmitted from tapping on the keys and regular usage of the device and ATM machines which may incur contaminants such blood, secretions, or other various sticky substances in the environment (Fukata et al., 2008).

Staphylococcus aureus are usually found on skin or in the nasal environment and only survives on dry skin on the outside of the body. They can appear on keyboards quite a bit as a result of usage. The computers keyboard and a mouse have a very dynamic environment. Food and eventually settle on the keyboard through the air or from physical contact. Cleaning our keyboard and mouse regularly is very important, although most people ignore it. Only about half of computer users' clean their computer keyboards at least once a month. Often time's keyboards are shared with multiple people; this makes it much more dangerous surface when it comes to passing diseases. If we use our own keyboard and mouse and nobody else uses it, the chances of that keyboard and mouse serving as a method of transmission is fairly small, but where sharing keyboards is concerned there is a higher probability of transmission occurring. Some of the microbes that can be found in the finger and in the hand are Enterobacter, Klebsiella sp, Aeromonas sp, Serratia sp, Pseudomonas sp (Wargo et al., 2006). An Automated Teller Machine (ATM) is a computerized telecommunications device that enables the clients of a financial institution to perform financial transactions without the need for cashier, human clerk or bank teller (Rasiah, 2010).Contamination of environmental objects and surfaces is a common phenomenon. Humans have a marked tendency to pick up microorganism from environmental object, and the hand has been shown to play a role in the transmission of organisms. The ATM machine is likely to be contaminated with various microorganisms due to their vast contact by multiple users. There is no restriction as to who has access to the facility and no guideline to ensure hygiene usage. But like all surfaces microbial colonization of these metallic keypads are eminent, particularly when there are no proper cleaning regimes in place for most of these facilities (Abban and Tano-Derah, 2011).

\section{Materials and Methods}

\section{Sample collection}

A total of 70 swabs were used for the study, 10 swabs from FDB ATM gallery in Ofirima the Faculty of Science, 10 from UBA ATM gallery in Abuja campus and 10 from FBN ATM on Choba. Twenty swabs were obtained from computer keyboards in Choba Park Business center, 20 from computer keyboards in Abuja campus.

\section{Isolation $S$. aureus}

Swabs collected were placed in a test-tube containing sterilized normal saline and a tenfold serial dilution was carried out. $0.1 \mathrm{ml}$ 
each of the samples were cultured on solidified nutrient agar plate (Oxoid) and mannitol salt agar. Plates were incubated at $37^{\circ} \mathrm{C}$ for 24 hours.Colonies were observed and counted in the plates. The isolates were sub cultured onto nutrient agar and incubated at $37^{\circ} \mathrm{C}$ for 24 hours. Biochemical test were carried out on the isolates for identification.

\section{Antibiotic susceptibility testing}

Antibiotic susceptibility testing was carried using the disc diffusion method, in brief; $3 \mathrm{mls}$ of normal saline was dispensed into test tubes and pure culture of $S$. aureus was inoculated into each of the test tubes containing the normal saline and the was compared with the prepared McFarland standard to check if they were of equivalence turbidity. After this, swab sticks were placed into each of the test tubes and then was drained a little to discard excess liquid before swabbing on the surface of the nutrient agar plate. The antibiotic Gram positive disc was gently picked from the container using sterile forceps and was placed at the center of the Muller Hinton (Oxoid) agar plates and incubated at $37^{\circ} \mathrm{C}$ for 24 hours. After incubation the plates the diameter zone of inhibition was measured.

\section{Plasmid Curing of $S$. aureus isolates}

The plasmid was cured by treatment with acridine orange according to the method of Brown (2000). Fifty (50) $\mathrm{mg}$ of acraidine orange was dissolved in $10 \mathrm{ml}$ of distilled water to prepare a stock solution which was stored in the refrigerator. From the stock solution $1 \mathrm{ml}$ of acridine orange solution and $0.5 \mathrm{ml}$ of glacial acetic acid was added to $50 \mathrm{ml}$ of distilled water for the preparation of the working solution.

Nutrient broth was prepared and supplemented with $0.1 \mathrm{mg} / \mathrm{ml}$ acridine orange. 20microliter of overnight culture of the bacteria was subcultured into $5 \mathrm{mls}$ of the nutrient broth containing acridine orange. The samples were incubated at $37^{\circ} \mathrm{C}$ for 72 hours. The isolates were sub - cultured onto Muller Hinton agar and an antibiotic sensitivity disc was placed on the media. The plates was inverted and incubated at $37^{\circ} \mathrm{C}$ for 24 hours. Zones of inhibition on the plate were measured using a transparent meter rule.

\section{Results and Discussion}

The findings of this study showed that ATM keyboards can be considered a source of bacterial Infections, similar to other contaminated surfaces in public places, such as telephones and door handles. Because most people with different levels of hygiene and health standards use these machines, they can be widely involved in absorbing, harboring, and transferring infectious microorganisms. Contaminated hands touching an ATM keyboard can transfer pathogens to the keyboard and bills, ultimately facilitating the spread of infectious diseases (Chirman et al., 2011; Rusin et al., 2002). A total of 70 swabs were obtained from ATM button and computer keyboard.

The bacterial load on the FDB ATM in Ofirima was from1.75 $\times 105-2.06 \times 105$ $\mathrm{CFU} / \mathrm{ml}$ and the bacterial load of UBA ATM button in Abuja campus range from $2.53 \times 105-2.75 \times 105 \mathrm{CFU} / \mathrm{ml}$. Further From the FBNATM machine in Choba area, the bacterial load was $2.25 \times 105-2.85 \times 105$ $\mathrm{CFU} / \mathrm{ml}$. The computers used by the computers (more than 12-18 persons were using that particular computer per day) in Choba showed a bacterial load of $2.25 \times 105$ $2.73 \times 105 \mathrm{CFU} / \mathrm{ml}$ and the computer used in Abuja campus by more than 5-10 persons per day showed a bacterial load of $1.95 \times 105$ $2.47 \times 105 \mathrm{CFU} / \mathrm{ml}$. From the study it was observed that the computers operated by multiple clients in the computer center at 
Choba and the FBN ATM in Choba are at high risk of transferring the pathogenic bacteria to the users and as ATM machines are operated by all sections of people frequently. Microorganisms can be transmitted into computer keyboards by the air the computer user breathes out; sneezing, digging nose during work by hands or other reactions leaves the keyboard contaminated. Detailed result of microbial area count of computer keyboard and. ATM button in Ofirima, Abuja campus and in Choba are shown in Table 1.

The microorganism were identified using their morphology characteristics and the biochemical test and the highest number of organism that occurred was Staphylococcus aureus followed by Klebsiella sp, Bacillus sp, Micrococcus sp, E.coli, Proteus vulgaris and Pseudomonas sp (Table 2).

All the Staphylococcus aureus were tested for their sensitivity to eight (8) types of antibiotics and it was observed that some of these Staphylococcus are highly resistant to standard antibiotics such as cloxacillin followed by Augmentin, erythromycin, and tetramycin. Gentamycin and chloramphenicol was highly susceptible as shown in Figure 1. The Staphylococcus isolates were also subjected to plasmid curing and sensitivity testing was to detect the role of plasmid in their resistance. Result obtained showed that Staphylococcus aureus was more susceptible to the antibiotics Chloramphenicol (98\%), Gentamycin (94\%), Cotrimoxazole (78\%), Streptomycin (60\%), Tetramycin (58\%) and Augmentin (52\%) as indicated in Figure 2.

ATM machines and computer keyboard have been used all over the world. Today the ATM machines are not only used for cash supply to the costumer but also they give service on different kind of monetary procedures such as money transfer, stock market transaction and bill payment. In a systematic review, Kramer et al., (2006),reported that many bacterial and viral pathogens could survive on the inanimate objects and such pathogens could cause epidemic infections as a result of direct or indirect transmission in hand-object susceptible patient. Dogon et al., (2008), found many types of pathogens on the computer keyboard which were used in education institutes and Tekerekoglu et al., (2011), reported that ATM buttons and computer keyboard carried multi-drug resistant hospital pathogens including, Acinetobacter sp, S. aureus and extendedspectrum beta lactamase ESBL-positive enterobacteriaceae and hence suggested that frequent disinfection on computer keyboard to reduce bacteria reservoir.

Table.1 Microbial Area Count of computer keyboard and ATM button in Ofirima, Abuja campus and Choba

\begin{tabular}{llccc}
\hline S/No & \multicolumn{1}{c}{ Area } & $\begin{array}{c}\text { Number of Swab } \\
\text { Samples }\end{array}$ & $\begin{array}{c}\text { Quantity(CFU/ml) } \\
(\text { minimum-maximum })\end{array}$ & $\begin{array}{c}\text { Isolate } \\
\text { Code }\end{array}$ \\
\hline 1. & Fidelity ATM gallery, Ofinima & 10 & $1.75 \times 105-2.06 \times 105$ & FIO \\
2. & UBA, ATM gallery, Abuja & 10 & $2.53 \times 105-2.75 \times 105$ & UIA \\
3. & First Bank ATM gallery, Choba & 10 & $2.25 \times 105-2.85 \times 105$ & FIC \\
4. & Computer keyboard in Abuja park & 20 & $1.95 \times 105-2.47 \times 105$ & CKA \\
5. & Computer keyboard in Choba & 20 & $2.25 \times 105-2.73 \times 105$ & CKC \\
\hline
\end{tabular}

KEY: FIO: Fidelity Isolate OfirimaUIA: UBA Isolate AbujaFIC: First Bank Isolate ChobaCKA: Computer Keyboard AbujaCKC: Computer keyboard Choba 
Table.2 Biochemical reaction test

\begin{tabular}{|c|c|c|c|c|c|c|c|c|c|c|c|c|c|c|c|c|c|c|}
\hline \multirow{2}{*}{$\mathbf{S} / \mathbf{N}$} & \multirow{2}{*}{$\begin{array}{l}\text { Isolate } \\
\text { Code }\end{array}$} & \multirow[b]{2}{*}{ 莺 } & \multirow[b]{2}{*}{ 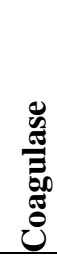 } & \multirow[b]{2}{*}{ 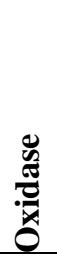 } & \multirow[b]{2}{*}{ } & \multirow[b]{2}{*}{$\frac{\circlearrowright}{\frac{0}{\sigma}}$} & \multirow[b]{2}{*}{ 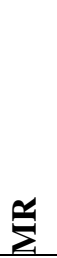 } & \multirow[b]{2}{*}{5} & \multirow[b]{2}{*}{ 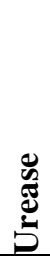 } & \multirow[b]{2}{*}{ 总 } & & \multicolumn{2}{|c|}{ TSIA } & \multicolumn{4}{|c|}{$\begin{array}{l}\text { Sugar } \\
\text { Fermentation }\end{array}$} & \multirow[t]{2}{*}{ Probable Genera } \\
\hline & & & & & & & & & & & & $\begin{array}{l}\vec{\Xi} \\
\frac{\vec{E}}{\omega}\end{array}$ & $\tilde{E}^{2}$ & $\tilde{I}$ & 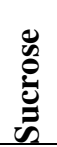 & 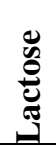 & 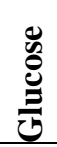 & \\
\hline 1 & FIO1 & + & + & - & + & - & - & + & - & - & A & A & - & - & + & + & + & S.aureus \\
\hline 2 & FIO2 & + & - & - & + & - & - & + & - & - & A & A & + & - & + & + & + & Klebsiella $s p$ \\
\hline 3 & FIO3 & + & - & - & + & - & - & + & - & + & A & B & - & - & - & - & + & Bacillus sp \\
\hline 4 & FIO4 & + & + & - & + & - & - & + & - & - & A & A & - & - & + & + & + & S.aureus \\
\hline 5 & UIA1 & + & - & - & - & + & + & - & - & + & A & A & - & - & + & - & + & E.coli \\
\hline 6 & UIA3 & + & - & - & + & - & - & + & - & - & A & A & + & - & + & + & + & Klebsiella $s p$ \\
\hline 7 & FIO5 & + & + & - & + & - & - & + & - & - & A & A & - & - & + & + & + & S.aureus \\
\hline 8 & UIA4 & + & - & - & - & + & + & - & + & + & A & A & + & + & - & - & + & Proteus sp \\
\hline 9 & FIC1 & + & - & - & - & + & - & + & - & - & A & A & + & - & + & - & + & Streptococcus $s p$ \\
\hline 10 & FIC3 & + & - & - & + & - & - & + & - & + & A & B & - & - & + & - & + & Serratia marsecens \\
\hline 11 & FIC5 & + & - & - & + & - & - & + & - & + & A & A & - & - & + & - & + & Micrococcus sp \\
\hline 12 & CKC2 & + & - & - & + & - & - & + & - & - & A & A & + & - & + & + & + & Klebsiella $s p$ \\
\hline 13 & UIA2 & + & - & - & - & + & - & - & - & + & A & A & - & - & + & - & + & S.aureus \\
\hline 14 & UIA5 & + & + & - & + & - & - & + & - & - & A & A & - & - & + & + & + & S.aureus \\
\hline 15 & UIA6 & + & + & - & + & - & - & + & - & - & A & A & - & - & + & + & + & S.auerus \\
\hline 16 & FIC2 & + & + & - & + & - & - & + & - & - & A & A & - & - & + & + & + & S.aureus \\
\hline 17 & CKC3 & + & - & + & - & + & - & + & - & - & A & B & - & - & - & - & + & Pseudomonas $s p$ \\
\hline 18 & FIC3 & + & + & - & + & - & - & + & - & - & A & A & - & - & + & + & + & S.aureus \\
\hline 19 & FIC6 & + & + & - & + & - & . & + & - & - & A & A & - & - & + & + & + & S.aureus \\
\hline 20 & CKA1-10 & + & + & - & + & - & - & + & - & - & A & A & - & - & + & + & + & S.aureus \\
\hline
\end{tabular}

Key: + = positive VP = VogesProskauer - = negative MR = Methyl Red

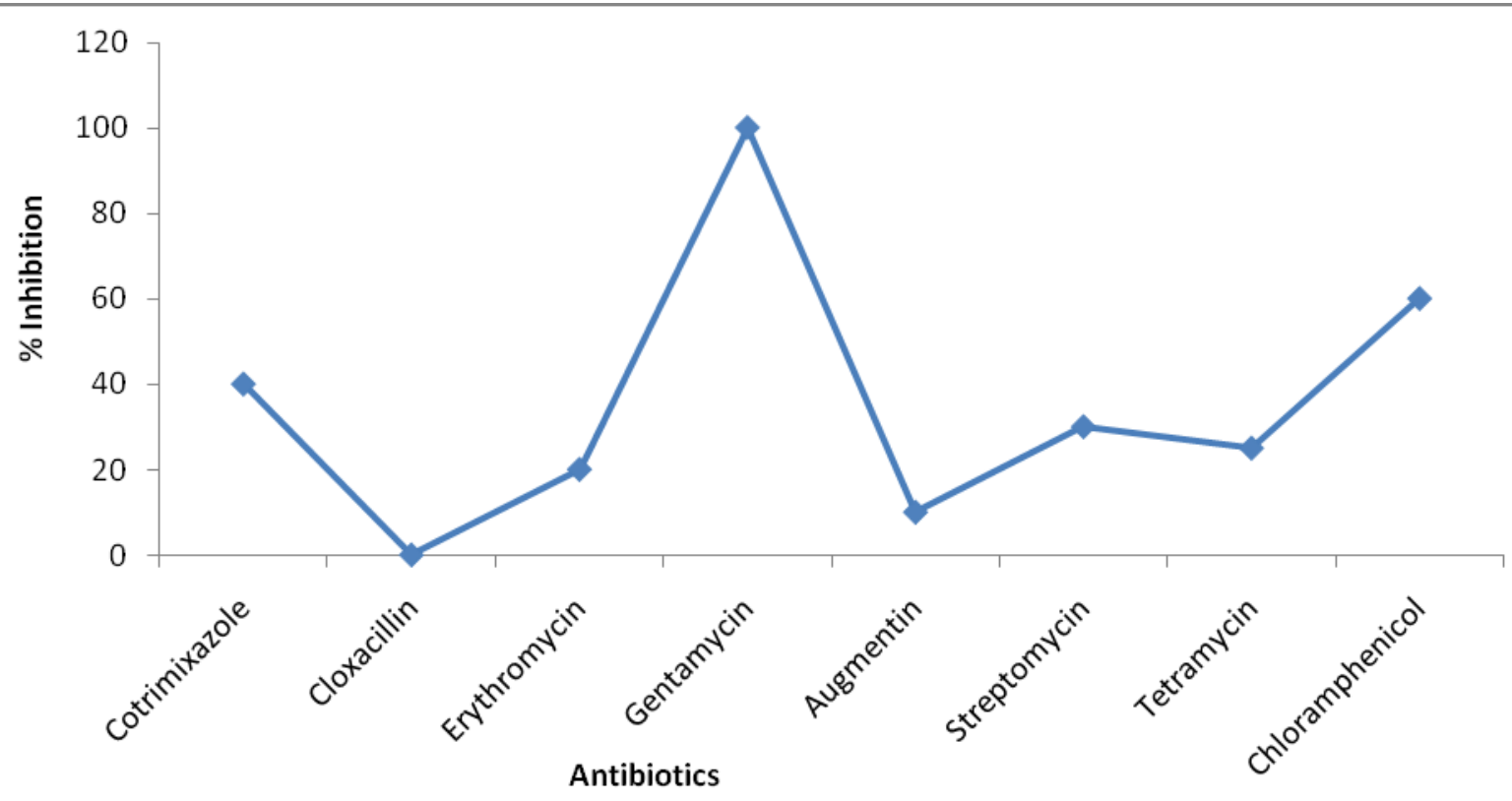

Figure 1: Percentage inhibition of $S$. aureus by antibiotics before curing. 


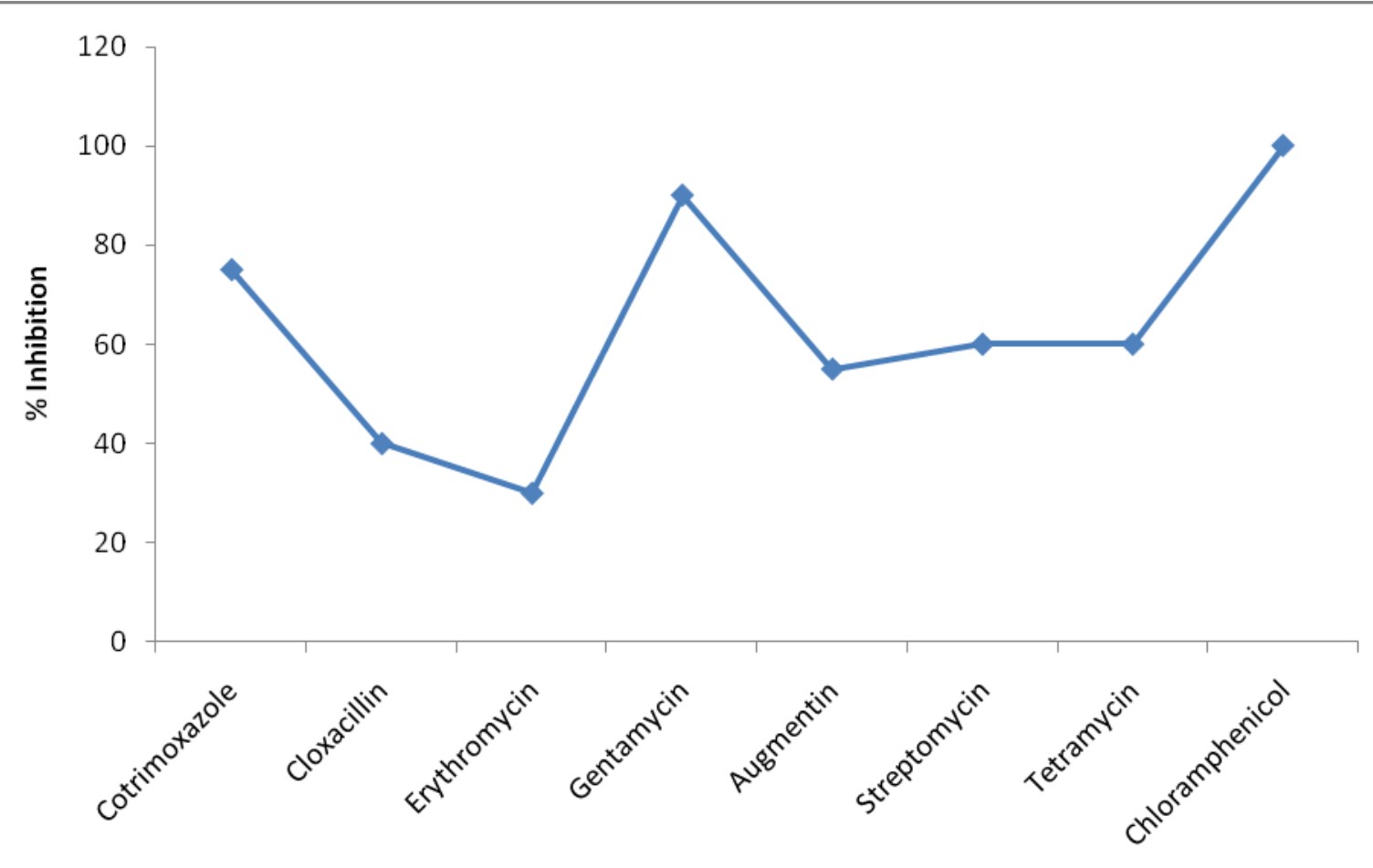

Antibiotics

Figure 2: Percentage inhibition of $S$. aureus by antibiotics after plasmid curing.

In this study, we found out that all the studied ATMs and computer keyboards were positive for a bacterial strain and is also in agreement with the study carried out by Abban and Tano- Debrah (2011) who reported the presence of Staphylococcus species, Escherichia coli and Klebsiella species on the keypads of ATM machines, together with Anastasiades et al., (2009) who reported that Staphylococcus aureus are prevalent on computer keyboards. Although the majority of the organisms detected were low virulent strains such as Bacillus sp, and some other pathogens including $S$. aureus, Klebsiella sp, E. coli, Proteus vulgaris and Micrococcus sp.

The present study revealed that $S$. aureus was the prevalent, this contradict the study carried out on ATM in Melli and Saderat banks in Iran by Mahmoudi et al., (2017) showed that the most frequently isolated bacteria were Staphylococcus epidermidis (18.5\%), Pseudomonas aeruginosa (18.5\%), Bacillus subtilis (16.9\%), Escherichia coli (9.2\%), Klebsiella spp. (12.3\%), Enterobacter spp. (3.1\%), Bacillus cereus (9.2\%), Staphylococcus aureus in 3 (4.6\%), and Micrococcaceae spp (7.69\%). All isolated bacteria were susceptible to gentamicin, cephalotin, tobramycin, amikacin, norfloxacin, and vancomycin while S. aureus resistance rate to trimethoprim/ sulfamethoxazole was $50 \%$. Their study also showed the presence of higher percentage of Gram positive organisms to Gram negative which is also in confirmatory to the present study. A study carried out by Mbajiuka (2015) on ATM keyboards in Nigeria revealed the presence Staphylococcus spp been the highest in occurrence $(82.5 \%$ (33), 
Bacillus spp $62.5 \%$ (25), Escherichia spp, $22.5 \%$ (9) Streptococcus spp 15\% (6). Fungal species were also isolated in their study such as Rhizopus spp with about $47.5 \%$ (19), Aspergillus spp, $22.5 \%$ (9) and Penicillin spp, $20 \%$ (8) were found on the keypads.

In the study carried out by Nwankwo and Offiah (2016) E. coli was the highest in occurrence $(26.5 \%)$ followed by $S$. aureus $(17.6 \%)$ and other organisms. This is contrary to our findings and some other researchers (Oluduro et al., 2011). Their findings of $E$. coli been the highest in occurrence may be due to the fact $E$. coli is a normal floral of the gastrointestinal tract and thus makes it easily to be picked up from toilet door handles etc. due to low hygiene measures. This may explain its preponderance as a bacterial contaminant of shared user hardware interfaces. It has also been associated with numerous infectious disease conditions and nosocomial infections. It follows that since users constantly touch interfaces there is every chance of introducing $E$. coli onto the interface in use. Methicillin resistant S.aureus is known to be notorious in their acquisition of resistance to drugs. Many strains of $S$. auerus carry a wide variety of multi drugs resistant genes on plasmid and so the resistances of S. aureus isolated from high touch areas such as the ATM, and computer keyboard have been widely reported. In this study, twenty Staphylococcus aureus was isolated and most of them were derived from First bank ATM gallery in Choba and computer keyboard in Abuja campus. The antibiogram result of this study showed that Staphylococcus aureus was $60 \%$ resistant to Cotrimixazole, Erythromycin (80\%), Gentamycin (10\%), Augmentin (90\%), Streptomycin (70\%), Tetramycin (70\%), Chloramohenicol (50\%). After the plasmid curing, the Staphylococcus aureus was 70\% susceptible to Cotrimixazole, follo $40 \%$ in Cloxacillin, $30 \%$ in Erythromycin, $100 \%$ in
Gentamycin, 50\% in Augmentin, 65\% in Streptomycin, $60 \%$ in Tetramycin and $100 \%$ in Chloramphenicol because the antibiotic resistance markers in $S$. aureus isolates are plasmid mediated. A study carried out by Nagajothi et al., (2015) Among S. aureus, $40 \%$ were resistant to Methicillin, $55 \%$ to penicillin followed by resistance to cotrimoxazole (27\%), gentamycin (25\%), erythromycin (20\%), amikacin (15\%), ciprofloxacin $(5 \%)$, and clindamycin $(5 \%)$. Twenty percent of CoNS were resistant to gentamicin followed by co-trimoxazole $(15 \%)$, amikacin $(10 \%)$, and ciprofloxacin (2\%). Methicillin resistance was not observed in CoNS. There is a need to minimize the antibiotics pressure that favors the selection of methicillin resistant $S$. aureus (MRSA) strains in ATM gallery and computer keyboard. Although S. aureus are resistant to other antibiotics most especially Erythromycin followed by Cloxacillin, Augmentin, Streptomycin and Tetramycin.

Most high-touch areas are touched by the bare hands of people who are in various hygienic conditions. The public should be conscious that ATM, computer keyboards and other public high touch areas are not only useful but they are source of microbes and thus preventive and good hygiene measures should be put into consideration when using these high touch areas.

\section{References}

Abban, S. and Tano-Derah. 2011. Automatic Teller Machines (ATMS) as Potential Source of Food-borne Pathogens - A Case from Ghana. Nature 9, 63-67.

Anastasiades, P., Pratt, T. L., Roussea, L.H., Steinberg, W.H., and Joubert, G. 2009. Staphylococcus aureus on computer mice and keyboards in intensive care units of the Universitas Academic Hospital, Bloemfontein and ICU staff's knowledge of its hazards and cleaning practices. South Afr. J. Epidemoiol. 
Infect, 24:22-26.

Chairman, K., Mathew, K. E., Padmalatha, C., andRanjit, A. J. 2011. Beware of pathogenic microbes in public utility devices. $J$ Microbiol Biotechnol Res. 1(3):85-90.

Dogan, M., Feyzioglu, B., Ozdemir, M., and Bayasal, B. 2008. Investigation of microbial colonization of computer keyboards used inside and outside hospital environments. Mikrobiyol. ssBul. 42(2):331-336.

Forbes, B. A., Sahm, D.F., and Weissfeld, A.S. Laboratory methods in basic mycology. Bailey and Scott's - Diagnostic Microbiology. 12 th ed., Ch. 50. Mosby Elsevier; p. 629-709.

Fukata, T. 2008.Anaesthetists' role in computer keyboard contamination in an operating room, J Hosp Infect, doi:10.1016/j.jhin.2008.05.23.

Hartman, B., Benson, M., and Junger, A. 2004.Computer keyboard and mouse as a reservoir of pathogen in an intensive care unit. J. Clin. Monit. Comp., 18: 7-12.

Kramer, et al.,2006. How long do nosocomial pathogens persist on inanimate surfaces? A systematic review. licensee BioMed Central Ltd., BMC Infectious Diseases,6:130.,

Mahmoudi, H., Arabestani, M. R., Alikhani, M. Y., IrajSedighi, Kohan, H. F., and Molavi, M. 2017.Antibiogram of bacteria isolated from automated teller machines in Hamadan, West Iran. GMS Hygiene and Infection Control. 12:Doc03. doi:10.3205/dgkh000288.

Mbajiuka, C. S. 2015. Isolation and identification of microorganisms with the use of ATM in Michael Okpora University of Agriculture Umudike (MOUAU) and its environs. World journalofPharmceutical research, 4: 85 - 99.

Nagajothi, J., Jeyakumari, D., Vigneshwaran, S., Praveen Kumar, R., Bharatwaj, R. S., andBagyalakshmi, R. 2015. Study of Prevalence of Microbial Contamination with its
Antibiotic Resistance Pattern in Automated Teller Machine in and around Puducherry, India, 1:27-30.

Nwankwo, O. E. and Offiah, J. C. 2016. Bacterial contamination of user interface of automated teller machine (ATM) of various banks in Umuahia metropolis Abia state Nigeria. International journal of tropical disease and health, 13: 1 -9.

Oluduro, A.O., Ubani, E. K., and Ofoezie, I.E. 2011. Bacterial assessment of electronic hardware user interfaces in Ile-ife, Nigeria. Journal of Basic and Applied Sciences, 93:585592.

Palmer, S. R.,and Bray, S. L. 2001. Longitudinal study of computer usage in flexible engineering education. Australian J. Edu. Tech., 17: 313-314.

Rasiah, D. 2011. ATM Risk Management and Control Guide for Finance Admin. 1:161-111.

Reynolds, K. A., Watt, P. M., Boone, S. A. and Gerba, C. P. 2005.Occurrence of bacteria and biochemical markers on public surfaces. Int. J. Environ. Health Res., 15: 225-234.

Rusin, P., Maxwell, S., and Gerba, C. 2002. Comparative surface-to-hand and fingertip-tomouth transfer efficiency of gram-positive bacteria, gram-negative bacteria, and phage. $J$ Appl Microbiol. 93:585-592.

Tekerekoglu MS., Duman, Y., Serindag, A., Cuglan, S.S., Kayasadu, H., Tunc, E., and Yakupogullari, Y. 2011. Do mobile phones of patients, companions and visitors carry multidrug-resistant hospital pathogens? Am. J. Infect. Control, 39:379-381.

Wargo, Mathew, Deborah Hogen. 2006. FungalBacterial Interaction: A Mixed Bag of Mingling. Microbes, current opinion in microbiology 9:359-364.

\section{How to cite this article:}

Agbagwa, O.E. and Ibeachu, O.C. 2017. Plasmid Profile and Antimicrobial Susceptibility Pattern of Staphylococcus sp. Isolated from High Touch Areas within the University of Port Harcourt Nigeria. Int.J.Curr.Microbiol.App.Sci. 6(11): 3434-3441. doi: https://doi.org/10.20546/ijcmas.2017.611.404 